\title{
Mas afinal, o que é Educação Física?
}

Prof. Adroaldo Gaya

Pergunta simples, já muitas vezes formulada. Entretanto quando nos deparamos com períodos de crise ou de transição, períodos que se caracterizam por serem difíceis de entender e de percorrer, períodos onde perdemos a clareza e a certeza do sentido de nossa tarefa, de nosso trabalho, "(...)é necessário voltar às coisas simples, à capacidade de formular perguntas simples, perguntas que, como Einstein costumava dizer, só uma criança pode fazer mas que, depois de feitas, são capazes de trazer uma luz nova a nossa perplexidade."

-Pois, é assim que percebo a necessidade de retomar a questão: Mas afinal, o que é educação física?

Se revisarmos a bibliografia encontraremos inúmeras tentativas de responder á questão. Podemos referir por exemplo, no contexto francês, a iniciativa de situá-la na perspectiva de uma ciência do movimento humano ou psicocinética sugerida por JEAN LE BOULCH e uma ciência da a çã o motrizou
Praxiologia por PIERRE BARLEBÁS.

$\mathrm{Na}$ Espanha JOSÉ MARIA GAGIGAL referiu-se a uma ciência da educação fís ic a sendo que M I G U E L VI GEN TE PEDRAZ, MORENO $\mathrm{e}$ LÓPEZ argumentam nesta mesma direção. .

No espaço de língua inglesa, salientamos as proposições, da educação física como disciplina acadêmica. GEORGE BROOKS, por exemplo, editou um livro onde autores como HENRY, F. M.; RARIGK, G.L; PARK, RJ., entre outros, discorrem sobre os aspectos epistemológicos e metodológicos de uma possível área de c o $\mathrm{nh}$ e c i m e $\mathrm{ntos}$ relativamente autônoma. Todavia, enquanto para alguns esta disciplina a c a dêmica deveria permanecer como educação física, para outros como NEWELL, K.M. deveria de nom in ar-se de c i n e s i o log i a ; cineantropologia para RENSON, R.; ciência do movimento, para HIGGINS, J.R, , BROOKE, J.D. e WHITING, H.T.A.; ciência do exercício, segundo $\mathrm{KATCH}$, F. I. ; e c i ê n - cia do desporto para DONALD SABBO. SAGE, G.H., GLASSEFORD, R.G. e $F E L T Z, \quad D$. L

$\mathrm{Na}$ Alemanha a perspectiva da ciência do desporto é amplamente abordada por HAAG, H., GRUPE, O., KIRSCH, A. e WILLIMCZIK, K.

$\mathrm{Na}$ mesma linha de investigação, todavia com referências na antropologia filosófica, tem destaque a obra de MEINBERG, E. cuja preocupação configura-se em delimitar o espaço da pedagogia do desporto como disciplina da ciência do desporto.

Originária da ex-RDA uma obra coletiva da Escola de Leipzig coordenada por BAUERSFELD, K.H. "Forschungsmethoden in den sport methodichen wissenschaftsdisziplinen" trata com detalhes as questões metodológicas da ciência do. desporto sobre o enfoque predominante de uma ciência do treino esportivo.

Na mesma perspecti- 
va de uma ciência do treino encontramos o livro editado por ADAM, Y. (editado em língua portuguesa) sob o título "Desporto e desenvolvimento humano", onde os autores de inspiração marxista discorrem sobre a organização da ciência do desporto.

Outro importante estudo abrangendo uma perspectiva histórica mas, referindo-se a conformação de um paradigma da cultura corporal, tendo como base empírica de observação a Dinamarca, é apresentado por HENNING EICHBERG:

No espaço de língua portuguesa, em Portugal, da mesma forma, a identidade da educação física tem sido periodicamente posta em causa. Aí também, é possível detectar posições diversas que, muitas vezes, assumem posições de radicalidade e que se expressam na própria negação, e na necessidade de exclusão -da expressão educação física, estou a lembrar das posições assumidas por MANUEL SÉRGIO em sua tese sobre a ciência da motricidade humana. Outros autores portugueses assumem posições diversas, FRANCISCO SOBRAL e JORGE PRENÇA configuramse em defensores da Educação Física. JORGE BENTO, JOSÉ MANUEL CONSTANTINO $\mathrm{O}$ ANTÔNIO MARQUES, convictos defensores do desporto, sugerem um projeto que supõe uma clara definição conceituai sobre educação física como disciplina cur- ricular e o desporto enquanto fenômeno cultural, embora Jorge Bento e Antônio Marques privilegiem o desporto como conteúdo da educação física.

No Brasil, VÍTOR MARINHO DE OLIVEIRA publicou em 1983 um ensaio como o título "O que é Educação Física?"No longo de seu livro nos diversos capítulos o autor questiona: Será Desporto? Será ginástica? Será política? Será educação? Será saúde?

No mesmo ano de 1983 , outro autor brasileiro JOÃO PAULO MEDINA publica obra, do mesmo modo provocadora e polêmica, en ti tula da "Educação Física cuida do corpo e.... 'mente'", onde impõe uma reflexão sobre a prática da educação física na sociedade brasileira."

Talvez possamos afirmar que estas duas obras marcaram no Brasil, a linha -

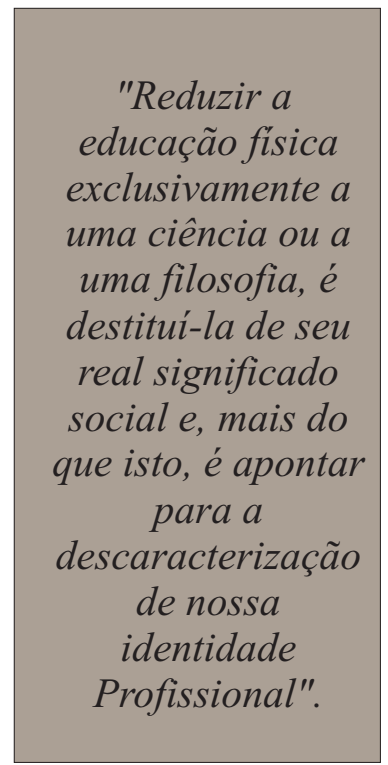

de partida sobre uma série de reflexões expressas em diversos artigos, ensaios e livros sobre o papel da educação física.

Por exemplo: LAMARTINE PEREIRA DA COSTA questiona: "Afinal o que faremos com a educação física? propõe sua reconstrução sobre a ótica do lazer e da recreação.

\section{SILVINO SANTIN} refere-se à educação física como uma filosofia de corporeidade. .

ALFREDO FARIA JR. afirma que, embora em seu discurso cotidiano os profissionais da educação física afirmem estreitas relações coma saúde, quando analisamos sua produção científica constatamos apenas uma "tênue relação "entre ambas.

Em outro artigo, evidenciei que a educação física ao pretender tornar-se uma disciplina das ciências da educação e/ou a saúde se descaracteriza e perde sua identidade.

Em recente ensaio, LUÍS AUGUSTO TEIXEIRA, retoma a questão propondo o estudo da motricidade humana como fonte de ordem para um tema científico, uma, profissão e um componente do currículo escolar, e sugere a adoção da cinesiologia como nome da área de estudo em substituição à educação física. 
Ihantes emergem em ensaios de autores com a autoridade de GO TANI ${ }^{35}$, JEFFERSON CANFIELD ${ }^{36}$, APOLONIO A. Do CARMO ${ }^{37}$, VALTER $\mathrm{B} R \mathrm{ACH} \mathrm{T}^{38}, \mathrm{H} \cup \mathrm{G}$ LOVISOLO ${ }^{39}$ e PAULO FARINATTI $^{40}$

Enfim, são muitos estudiosos que debruçam-se sobre o tema.

Todavia, embora aparentemente este quadro possa representar um conjunto de múltiplas concepções, ao analisarmos com mais rigor seus argumentos podemos perceber que, com pequenas nuances, elas traduzem convicções que se expressam em duas principais tendências:

a primeira, amplamente dominante, pretende configurar a educação física como uma ciência relativamente autônoma - uma disciplina acadêmica e/ou científica.

a segunda, cética quanto as pretensões de hegemonia do conhecimento científico, pretende a educação física como uma filosofia da corporeidade..

Da primeira tendência decorrem duas perspectivas:

$1^{\circ}$. É o caso da ciência da motricidade humana, ciências do exercício, cinesiologia ou cineantropologia, a psicocinética ou praxiologia, que pretendem reunir dentro de um único espaço de investigação as diferentes formas e expressões acultura corporal. Ou seja, querem
Dar aulas de educação física pressupõe

inicialmente uma intencionalidade, uma determinada visão de mundo, enfim, uma concepção filosófica ".

constituir teorias capazes de abranger o desporto, a dança, a ergonomia, o teatro, a expressão corporal, os jogos, as atividades circenses e laborais; além de agregar todas as disciplinas científicas que, num determinado momento, trate desses objetos.

$2^{\circ}$. É o caso das ciências do desporto ou ciência do treino desportivo, que embora já limitando a abordagem a uma prática corporal e motora específica, pretendem a criação de um espaço capaz de albergar' toda $\mathrm{e}$, qualquer disciplina científica que, de alguma forma, trate questões referentes ao desporto. decorrem:

Da segunda tendência,

$1^{\circ}$ Uma perspectiva existencialista, que configura à educação física um dis- curso filosófico da corporeidade, dando ênfase ao lúdico, a sexualidade, as práticas alternativas de expressão corporal;

$2^{\circ}$ Uma perspectiva cultura lista, que prevê a .reconstrução da educação física na ótica do lazer, dos jogos populares e tradicionais.

Mas afinal! $O$ que é educação física? Será ciência ou será filosofia?

\section{A EDUCAÇÃO FÍSICA COMO UMA DISCIPLINA NORMATIVA}

$\mathrm{O}$ que pretendo sugerir como hipótese nessa comunicação é.que estas tendências que inferem a possibilidade de reduzir a e d u c a ç ã o fí s i c a exclusivamente a uma ciência ou a uma filosofia, acabam por destituí-la de seu real significado social e, mais do que isto. apontam para a descaracterização de nossa identidade profissional.

Vamos aos argumentos.

Parto do seguinte pressuposto: a educação física se consubstancia numa pedagogia, ou seja, numa disciplina normativa que se concretiza através de uma prática pedagógica com objetivos formativos. Deste modo, portanto, ela não, pode se resumir exclusivamente a princípios gnosiológicos particulares, sejam de cunho científico ou filosófico. 
Permitam-me detalhar um pouco mais esta asserção.

Inicialmente, o que significa perceber a educação física como uma pedagogia ( práxis formativa)? Em nosso entendimento, significa configurá-la como um c o n j u n to d e c o n h e c i m e n to s (disciplina), que enuncia de forma concreta (através de nossas aulas, enfim de nossa ação ou prática pedagógica) um conjunto de fórmulas abstratas (preceitos éticos, morais, políticos e estéticos) que indicam como algo deve ser, em toda a situação em que se admite juízos.

Este entendimento supõe, portanto, que a educação física é concretamente ação. A educação física se operacionaliza na prática pedagógica. Torna-se normativa, de valores quando julga, por exemplo entre o certo e o errado, o,bem e o mal, o bonito e o feio, o disciplinado e o indisciplinado, etc.; tornase normativa de conhecimentos quando seleciona o que deve ser ensinado ou aprendido como relevante na cultura física, os hábitos de vida, o desporto e a promoção da saúde, por exemplo; e torna-se normativa de atitudes, habilidades e condutas quando define esteriótipos corporais, modelos de movimento e atitudes posturais.

To d a via, nã o podemos olvidar que, entendida como disciplina normativa, fica implícito q u e a e d u c a -
"A prática da educação física efetua-se segundo principios advindos do conhecimento cientifico. Os fundamentos biológicos, psicológicos, sociológicos, etc., são determinantes de sua práxis".

ção física fundamenta-se, a princípio, num conjunto de valores. Os conhecimentos as atitudes, as habilidades e as condutas configuramse tendo com referência uma axiologia, um sistema de valores, enfim, pressupostos de origem filosófica ou da antropologia filosófica.

Portanto, o dar aulas de educação física pressupõe inicialmente uma intencionalidade, uma determinada visão de mundo, enfim, uma concepção filosófica.

Não obstante, se é um fato que a prática da educação física exige pressupostos filosóficos, isto não significa que se possa reduzi-la a um subproduto da filosofia. Mesmo que se pretenda uma filosofia da corporeidade ou da cultura corporal. Isto por-que, antes de mais nada, a educação $f$ i $s$ i $c$ a é uma prática de intervenção no mundo concreto, enquanto a filosofia não assume esta prerrogativa. A educação física intervém num mundo real, no mundo tal como ele é, e não apenas permanece na abstração do como deveria ser.

Por outro lado, da mesma forma é evidente que a prática da educação física efetua-se segundo princípios advindos do conhecimento científico. Os fundamentos biológicos, psicológicos, sociológicos, etc., são determinantes de sua práxis. Não obstante enquanto expressão do conhecimento científico definida a partir de objetos e metodologias específicas a educação física torna-se um domínio onde mais flagrantemente ocorrem as fraturas emergentes oriundas da cobiça incessante dos múltiplos projetos científicos, os quais desenvolveram, antes de mais nada, suas estratégias de hegemonia.

Portanto, nesse quadro onde convergem conteúdos e interesses diversos (da biologia, da antropologia, da sociologia, da psicologia, etc.) configura-se um espaço multidisciplinar onde se percebe uma profunda ausência de objetivos e objetos comuns, ficando desta forma, destituídas de $\mathrm{u} \mathrm{m}$ a d e f i n i çã o e pistemológica e metodológica capaz de responder às necessidades inerentes aos intervenientes da educação física.

D e s t e modo, enquanto no âmbito do conhecimento científico se discute as definições de seus objetos teóricos, ou $\mathrm{sej} a$, e n qu a n to 
os discursos científicos procuram responder aos critérios inerentes aos juízos epistemológicos, a prática da educação física enfrenta o desafio que, entretanto, se coloca ao homem concreto.

\section{A EDUCAÇÃO FÍSICA COMO PROJETO PEDAGÓGICO}

Portanto, reduzir a educação física a seus pressupostos filosóficos, ou a um conjunto de conhecimentos oriundos de suas diversas disciplinas científicas, descaracteriza seu efetivo papel social enquanto um projeto pedagógico.

A educação física, devemos reconhecer, é educação. É parte da educação geral, isto se entendermos como e d u c a ç ã o o desenvolvimento da personalidade, e o desenvolvimento da personalidade como o desenvolvimento das capacidades físicas, motoras, intelectuais, afetivas e morais dos seres humanos visando sua atuação na sociedade.

Se ndo a s s i m portanto, ela configura-se num percurso entre a filosofia e a ciência mas em que a primeira não constitui um princípio nem a segunda um fim. Entre uma e outra acaba por não haver oposição, confronto ou distância sequer. Há antes correlação, diálogo e integração.

A educação física enquanto limitada à filosofia, permanece na abstração de um discurso e s p e culativo de cunho axiológico.

A educação física enquanto limitada à ciência, permanece na proposição e validação de técnicas e estratégias de atuação.

Todavia a educação física enquanto um projeto pedagógico faz interagir o conhecimento filosófico e o científico na ação de ensinar, na ação de conduzir (que é o próprio significado etimológico da pedagogia).

A educação física enquanto projeto pedagógico exige da filosofia seus fundamentos axiológicos; exige da ciência a seleção e validação de conteúdos e conhecimentos capazes de estruturarem técnicas de efetiva intervenção. Todavia não se encerra nestas formas de conhecimento. É necessário concretizá-los, o que só é possível através da ação pedagógica, através de nossas aulas e de nosso compromisso com a formação da personalidade de indivíduos humanos.

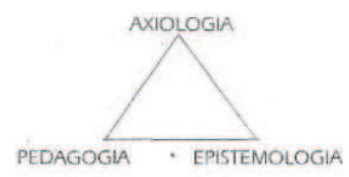

Enfim, elevemos perceber a educação física como uma pedagogia no âmbito d e u m projeto antropológico. Devemos ter claro que a educação física é uma intervenção no real concreto a partir de objetivos práticos. Em conclusão, gosta- ria de afirmar minha crença i $n$ a b a I á v e I n a indispensável relevância da educação física como disciplina curricular à medida que ao configurarse numa ação formativa de v a lores/a t i tudes, habilidades e condutas humanas, que se expressa no ato pedagógico de um agente pedagógico (o professor de educação física), que a partir dos elementos da cultura física (o desporto, o jogo, a dança, a ginástica) impõe uma intencionalidade (sistema de valores estando ou não consciente disto o agente pedagógico) $\mathrm{qu} e \mathrm{~s} e \mathrm{torn} a$ imprescindível (devido principalmente a especificidade da educação física) na formação de crianças e jovens.

Pensemos a educação física como um projeto pedagógico e, assim, e $\mathrm{s} \quad \mathrm{t}$ a $r$ e $\mathrm{m} \quad \mathrm{o}$ reestabelecendo nossa identidade profissional. $\mathrm{O}$ professor de educação física, um educador, um pedagogo.

\section{REFERÊNCIAS BIBLIOGRÁFICAS}

BAUERSFELD, K.H. (coord.). (1989): Forschungsmethoden in den sport-methodichen wissenchatsdisziplinen.

Leipzig, Deutsche Hochschule Für Kõperkultur Leipzig.

BENTO, J.O: (1987). Desporto matéria de ensino. Lisboa, Caminho.

BRACHT, V. (1992): Educação Física e aprendizagem social. Porto Alegre, Magister.

BROOKE, J.D. et WHITING, H.T.A. (1973): Human Movement. A field of study. London, Henry Kimpton.

BROOKS, G..A. (ed.).' (1981): Perspectives on the academic d i s cipline of 
physical education. Champaign, Human Kinetics,

CAGIGAL, J.M. (1968): La Educación Física, ciência? Citius, Altius, Fortius. n¹0. p. 165-180.

CAGIGAL， J.M. (1979): Cultura intelectual y cultura física. Buenos Aires, Kapeluz.

CANFIELD, J. T. (1988): Pesquisas e pós-graduação em educação física. In: PASSOS, S.C.E. (org.). Educação Física e esportes na Universidade. Brasília, MEC p.405-418.

CANFIELD, J.T. (Í993): A ciência do movimento humano como área de concentração de um programa de pósgraduação. Santa Maria, UFSM. (mimeo).

CARMO, A.A. (1987): Estatuto epistemológico da Educação Física. Caderno pedagógico de educação física. Curitiba, Secretaria de Estado de Educação do Paraná.

CARVALHO, A.D. (1992): A Educação como projecto antropológico. Porto, Afronta mento, p.7.

CONSTANTÍNO, J.M. (1992). Desporto português. As soluções adiadas. Lisboa, Livros Horizonte.

COSTA, L.P. Afinal o que faremos com a educação física? In: OLIVEIRA, V.M. (org.), (1987). Rio de. Janeiro, Ao Livro Técnico.

COSTA, L.P. A reinvenção da educação física e do desporto segundo paradigmas dó lazer e da recreação. (1987). Lisboa, DGD

EICHBERG, H. (1989): Body culture as paradigma. The Danisch sociology of sport. International Rev. for sociology of Sport. München. Vol.24, n¹, p.44-59.'

FARIA JÚNIOR, A. Professor de educação física, licenciado generalista. In: OLIVEIRA, V.M. (1987) Op. Cit.

FARINATTI, P. Produção do conhecimento em educação física. In: FARJA JR., A. et FARINATTI, P. (org.), (199í): Pesquisa e produção de conhecimento em educação física: Livro do ano 1991/SBDEF. Rio de Janeiro, Ao livro Técnico.

GAYA, A.C.A. (1989). Educação Física: educação e saúde?(1989). Revista da Educação Física/UEM-V 1, nº! (1989), p.36-38, Maringá, Universidade Estadual de Maringá.

HAAG, H., GRUPE, O. et KIRSCH, A. (eds), (1992): Sport Science in Germany: An interdisciplinary a $\mathrm{nth}$ ology. B e r I i n
Heidelberg, Spring-Verlag.

HIGGINS, J.R. (1989):- Moviment science. In: Journal of Physical Education, Recreation and Dance. Vol. $60, n^{\circ} 8$, p.66-67.

KATCH, F. I. (1989): Exercise science it's more than just a name change. In: Journal of. Physical Education, Recreation and Dance, Vol. 60, $n^{\circ} 8, p$. 71 *72.

LE BOULCH, J, (1971): Vers une scien du mouvement humain. Paris.

LÓPEZ, J.R. (1991): El método explicativo en las epistemologías regionales de la actividad física. Revista Apunts Educació Física i Esports. Barcelona, $n^{\circ}$ 24. p. 19-26.

LOVISOLO, H. (1992): Educação Física' como arte da mediação. Contexto \& Educação,. Unijuí, 7(29): p.39-51

MARQUES, AT. (s.d.): O treino desportivo como área científica. Porto, FCDEF-UP. (mimeo.)

MEDINA, J.P.S. (1985). A educação física cuida do corpo...e "mente". $4^{a}$ ed. Campinas, Papirus.

MEINBERG, E. (1991): Ciência do desporto: balanço e perspectivas. In: BENTO, Jorge <Ó e MARQUES, Antônio (org.) As ciências do desporto e a prática desportiva. Porto, Universidade do Porto/Faculdade de Ciências do Desporto e da Educação Física, 1991. v.l. p. 41-51.

MORENO, J.H. (1990): La actividad física y el deporte en el âmbito de la ciência. Revista Apunts Educació Física i Esports. Barcelona, $\mathrm{n}^{\circ} 22$, p.510.

NEWELL, K.M. (1989): Kinesiology. In: Journal of Physical, Education, Recreation and Dance. Vol. 60, $\mathrm{n}^{\circ} 8$, p.69-70.

NEWELL, K.M. (1990): Kinesiology: the label for the study of physical activity in higher education. In: Quest, Vol. 42, n³, p.269-278.

OLIVEIRA, V.M. (1983). O que é educação física. São Paulo, Brasiliense.

PARLEBÁS, P. (1981): Contribuition à um lexique commemté en science de l'áction motrice. Paris, INSEP, Minisère de la Jeunesse, des sport et des loisirs.

PARLEBÁS, P. (1971): Pour une épisté-mologie de l'education physique. Revista E.P.S., $n^{\circ} 110$, p. 1522.

PARLEBÁS, P. (1990): Épistémologie des activités physiques et sportives. Paris, PUF.
PEDRAZ, M.V. (1987): Teoria pedagógica de la actividad física. Madrid, Gymnos.

PROENÇAJ. (1993): Formação inicial: Complexidade, equívocos e paradoxos. In: Revista Horizonte, Vol. X. $n^{\circ} 55$, maio-junho, p.3-6. Lisboa.

QUEST, Vol. 39, n³, dezembro de 1987. SAGE, G.H., p. 255-281; GLASSEFORD, R.G., p. 282-295 e FELTZ, D.L., p. 243-254.

RENSON, R. (1989): From physical education to kinantropology: a quest for academic and professional identity. In: Quest, Vol. 41, p. 235-256.

SABO, D. (ed). (-H993\}: Sport Science Review. Sport sociology, Vol. 2, $n^{\circ} 1$, Illinois, Human Kinetics Publishers.

SANTOS, B.S. (1991): Um discurso sobre as ciências. $5^{\text {a }}$ ed. Porto, Afrontamento, p.6.

SANTIN, S. (1987). Educação Física. Uma abordagem filosófica da corporeidade. Ijuí, Unijuí:

SCHINDLER et alii. (1977): A ciência do desporto e suas perspectivas de evolução. In: ADAM, Y. Desporto e desenvolvimento humano. Lisboa, Seara Nova, 1977. p. 95-118.

SÉRGIO, M. (s.d). Para uma epistemologia da motricidade humana.

Lisboa. Compendium.

SOBRAL, F.( 1976). Para uma teoria da educação física. Lisboa, Diabril.

TANI, G. (1988): Pesquisa e Pósgraduação em educação física, in: PASSOS, S.C.E. (org.). Educação Física e esportes na Universidade. Brasília, MEC, p. 379-394.

TANI, G. (1990): Relatório "de visita ao centro de Educação Física e desportos da Universidade Federal de Santa Maria, (não publicado)

TEIXEIRA. LA (1993): Estudo da motricidade humana como fonte de ordem para um tema científico, uma profissão, e um componente do currículo escolar. In: Revista Paulista de Educação Física. Vol. 7, janeiro/junho, $n^{\circ 1}$,p77-91.

\section{UNITERMOS}

Educação Física, disciplina curricular, pedagogia, intencionalidade pedagógica.

\section{ADROALDO GAYA}

Professor Adjunto da Escola Superior de Educação Física da Universidade Federal do Rio Grande do Sul. Doutor em Ciências do Desporto pela Universidade do Porto. 